\title{
Intimal medial thickness of the carotid artery in South Indian diabetic and non-diabetic subjects: the Chennai Urban Population Study (CUPS)
}

\author{
V.Mohan, R. Ravikumar, S. Shanthi Rani, R. Deepa \\ Madras Diabetes Research Foundation, Gopalapuram, Chennai, India
}

\section{Abstract}

Aim/hypothesis. Increased intimal medial thickness (IMT) of the carotid arteries is considered a useful marker of atherosclerosis. The aim of this study was to compare the intimal medial thickness values in urban non-diabetic and diabetic South Indian subjects who have a high risk of coronary artery disease.

Methods. The subjects for this study were 140 diabetic and 103 non-diabetic control subjects matched with them for age and sex selected from The Chennai Urban Population Study which is an ongoing epidemiological study. Intimal medial thickness of the right common carotid artery was determined using high resolution B mode ultrasonography.

Results. The mean intimal medial thickness values of the diabetic subjects $(0.95 \pm 0.31 \mathrm{~mm})$ were significantly higher than those of the non-diabetic $(0.74 \pm 0.14 \mathrm{~mm})$ subjects $(p<0.001)$. Both in the normal and diabetic subjects, these values increased with age. At any given age, the diabetic subjects had higher values than the non-diabetic subjects but the difference reached statistical significance after age 50 years $(p<0.05)$.

Intimal medial thickness showed a correlation with age, total cholesterol, LDL cholesterol, waist:hip ratio and systolic blood pressure in non-diabetic subjects and with age and duration of diabetes in the diabetic subjects. Multivariate linear regression analysis showed that age and diabetes were the major risk factors for intimal medial thickness.

Conclusion/interpretation. Diabetic subjects have higher intimal medial thickness values than non-diabetic subjects. Diabetes and age are the most important risk factors associated with increased intimal medial thickness in this South Indian cohort. [Diabetologia (2000) 43: 494-499]

Keywords Intimal medial thickness, epidemiology, coronary artery disease, risk factors, Type II diabetes, macrovascular disease, carotid wall thickness.
Measurement of the carotid intimal medial thickness (IMT) is being increasingly used as a non-invasive marker of atherosclerosis [1-3]. It has also been shown that the IMT measurements correlate strongly

Received: 15 June 1999 and in final revised form: 30 December 1999

Corresponding author: Professor V. Mohan, MD, PhD, Madras Diabetes Research Foundation, 35, Conran Smith Road, Gopalapuram, Chennai - 600 086, India

Abbreviations: IMT, Intimal medial thickness; CUPS, Chennai urban population study; HOMA, homeostasis model assessment. with future development of myocardial infarction and stroke $[4,5]$. Asian Indians have a very high prevalence of premature coronary artery disease [6-8] and diabetes $[9,10]$ and the 'epidemic' is on the increase [11]. Recent estimates have ranked India number one in the world in the number of diabetic patients in any given country [12]. One of the important complications of diabetes is atherosclerosis leading to coronary artery disease and strokes. There are no published studies on IMT in Asian Indians. This paper presents data on IMT in a population-based study done in diabetic and non-diabetic subjects in Southern India. 


\section{Subjects and methods}

The Chennai Urban Population Study (CUPS) is an ongoing epidemiological study in Chennai (formerly Madras) the fourth largest city in India with a population of about six million. The aim of CUPS is to obtain prevalence data on diabetes and its complications, hypertension, hyperlipidaemia and coronary artery disease and their risk factors among people of different socio-economic strata in urban Chennai in the Tamil Nadu state in Southern India. Briefly, two defined residential colonies representing the middle and lower income groups in Chennai were selected for their geographic convenience, social differences and the local support available which would facilitate future incidence studies. An initial survey was done in all family members using a questionnaire to obtain the basic census details such as number of people, age, sex and presence or absence of diabetes.

All people above the age of 20 years living in these colonies were invited to participate in a screening programme which included fasting and 2-h (post 75-g oral glucose load) plasma glucose concentrations except in known diabetic subjects in whom only fasting plasma glucose was measured. Other tests were fasting and 2-h serum insulin estimates, a complete lipid profile including total serum cholesterol, serum triglyceride and serum HDL cholesterol. The LDL cholesterol was calculated using the Friedewald formula [13]. Biochemical analysis were done on Ciba Corning Express Plus Auto Analyser (Corning, Medfield, Mass., USA) using kits supplied by Boehringer Mannheim (Mannheim, Germany). Glycated haemoglobin $\left(\mathrm{HbA}_{1 \mathrm{c}}\right)$ was estimated by high pressure liquid chromatography using the Variant machine (Bio-Rad, Hercules, Calif., USA). Serum insulin concentrations were estimated using Dako kits (Dako, Glostrup, Denmark). Insulin resistance was calculated using the homeostasis model assessment (HOMA) model as follows [14]:

$\mathrm{IR}=\frac{\mathrm{FI} \times \mathrm{FPG}}{22.5}$

$\mathrm{FI}=$ Fasting insulin concentrations $(\mu \mathrm{IU} / \mathrm{ml})$ and $\mathrm{FPG}=$ fasting plasma glucose $(\mathrm{mmol} / \mathrm{l})$

Physical examination included height and weight measurements and the body mass index was calculated. Waist and hip measurements were done in the standing position and the waist:hip ratio was calculated. Waist was measured as the smallest horizontal girth between the costal margins and the iliac crests and hip as the greatest circumference at the level of greater trochanters. The blood pressure was recorded in the sitting position in the right arm with a mercury sphygmomanometer (Diamond Deluxe BP apparatus, Pune, India). Two readings were taken 5 min apart and the mean of the two was taken as the blood pressure.

Out of the total of 1339 people above the age of 20 years living in the two colonies, $1262(90 \%)$ participated in the initial screening programme. Of these 91 were known to have diabetes at the time of the survey. After the screening, an additional 61 subjects were diagnosed as having diabetes based on World Health Organisation (WHO) criteria [15]. Thus there were a total of 152 diabetic patients in the population studied. All these diabetic subjects were invited to participate in the studies on carotid intimal medial thickness and of them $140(92.1 \%)$ participated in the study. There were no significant differences in age, sex distribution, body mass index, fasting plasma glucose, glycated haemoglobin or duration of diabetes between the 140 participants and the 12 non-participants. All 140 subjects had Type II (non-insulin-dependent) diabetes mellitus as defined by absence of ketosis and adequate insulin reserve.
From the non-diabetic cohort of the population defined as those with normal glucose tolerance, control subjects matched for age and sex with diabetic subjects (frequency matching was done) were also requested to participate. A total of 103 control subjects participated in the study.

Intimal medial thickness study. The intimal plus medial thickness of the carotid arteries was determined using a high resolution B mode ultrasonography system (Logic 400 GE, Milwaukee, Wis., USA) having an electrical linear transducer midfrequency of 7.5 MHz. The axial resolution of the system was $0.3 \mathrm{~mm}$. The images were recorded, as well as photographed. The scanning was done for an average of $20 \mathrm{~min}$.

The intimal plus medial thickness (IMT) as defined previously $[1,16]$ was measured as the distance from the leading edge of the first echogenic line to the second echogenic line. The first echogenic line represents the lumen intimal interface and the second line is produced by the collagen - containing upper layer of the intimal adventitia. At each longitudinal projection, determinations of IMT were conducted at the side of greatest thickness and at two points $1 \mathrm{~cm}$ upstream and $1 \mathrm{~cm}$ downstream from the side of greatest thickness as described previously [17]. The mean of the six IMT measurements (three from the left and three from the right) was used as the representative value for each subject.

All scannings were conducted by a trained ultrasonologist (R. Ravikumar) who was unaware of the clinical status of the study subjects. The mean coefficient of variation for the six IMT measurements was $7.8 \%$ for the non-diabetic subjects and $8.4 \%$ for the diabetic subjects. The reproducibility of the IMT measurement was examined by conducting another scanning 1 week later on seven participants by the same sonographer. The mean difference in IMT between the first and second measurements was $0.04 \mathrm{~mm}$, and the standard deviation was $0.02 \mathrm{~mm}$, showing good reproducibility. The reproducibility of IMT measurements were analysed by calculating the intraclass correlation coefficient of reliability. There was a fairly good correlation between the IMT measurements, $(r=0.74)$.

Intimal medial thickness measurements were also carried out on the internal carotid artery on a subgroup of non-diabetic ( 10 men / 10 women) and diabetic ( 10 men / 10 women $)$ subjects and compared with the IMT of common carotid artery. The mean IMT values of the common carotid artery and the internal carotid artery in diabetic subjects were $0.92 \pm 0.11 \mathrm{~mm}$ and $0.74 \pm 0.10 \mathrm{~mm}$, respectively $(r=0.52$, $p<0.0001)$. In the non-diabetic subjects, the mean IMT values of the common carotid and internal carotid arteries were $0.78 \pm 0.09 \mathrm{~mm}$ and $0.62 \pm 0.11 \mathrm{~mm}$ respectively $(r=0.59$, $p<0.0001)$.

Statistical analysis. Student's $t$ test or analysis of variance as appropriate was used for comparing mean values of selected variables in diabetic and non-diabetic subjects and the chi-squared test was used for comparing proportions.

Due to their skewed distribution, fasting serum insulin concentrations were transformed to natural logarithms and the values were expressed as geometric mean (SD). Pearson's correlation analysis was carried out to determine the correlation of IMT with the variables of age, glycated haemoglobin, serum cholesterol, serum triglycerides, HDL cholesterol, insulin resistance [homeostasis model assessment (HOMA)], waist:hip ratio, body mass index and diabetes as independent variables. Univariate linear regression analysis was done using IMT as the dependent variable and age, glycated haemoglobin, serum cholesterol, serum triglycerides, HDL cholesterol, insulin resistance (HOMA), waist:hip ratio, body mass index and diabetes as independent variables. Multivariate linear regression 
Table 1. Clinical features of study groups

\begin{tabular}{|c|c|c|c|}
\hline Variables & $\begin{array}{l}\text { Non diabetic } \\
(n=103)\end{array}$ & $\begin{array}{l}\text { Diabetic } \\
(n=140)\end{array}$ & $p$ value \\
\hline Age (years) & $52 \pm 13$ & $55 \pm 12$ & NS \\
\hline Men $(\%)$ & $53.4 \%$ & $51.4 \%$ & - \\
\hline Serum cholesterol $(\mathrm{mmol} / \mathrm{l})$ & $4.96 \pm 1.10$ & $5.26 \pm 1.04$ & 0.031 \\
\hline Serum triglycerides $(\mathrm{mmol} / \mathrm{l})$ & $1.48 \pm 0.73$ & $2.03 \pm 1.27$ & $<0.001$ \\
\hline Serum HDL cholesterol (mmol/l) & $1.09 \pm 0.29$ & $0.99 \pm 0.31$ & 0.011 \\
\hline Body mass index $\left(\mathrm{kg} / \mathrm{m}^{2}\right)$ & $22.9 \pm 4.3$ & $24.5 \pm 4.5$ & 0.006 \\
\hline Systolic BP ( $\mathrm{mm} \mathrm{Hg})$ & $130 \pm 18$ & $133 \pm 15$ & NS \\
\hline Diastolic BP (mm Hg) & $82 \pm 10$ & $84 \pm 9$ & NS \\
\hline Waist: hip ratio & $0.86 \pm 0.08$ & $0.90 \pm 0.13$ & 0.006 \\
\hline Smoking (\%) & $7 / 103(6.8 \%)$ & $13 / 140(9.3 \%)$ & NS \\
\hline Fasting serum insulin $(\mu \mathrm{U} / \mathrm{l})$ & $3.7(2.7)$ & $5.1(2.5)$ & 0.010 \\
\hline
\end{tabular}

Fasting serum insulin concentrations and insulin resistance are expressed as geometric mean (SD). BP = blood pressure

analysis was carried out using the variables which proved to have a significant association with IMT in the univariate analysis. A $p$ value of less than 0.05 was considered significant. All statistical analyses were done on SPSSC (Version 4.01, SPSS, Chicago).

\section{Results}

Table 1 shows the clinical and biochemical features of the study groups. The BMI of the diabetic subjects was greater than the non-diabetic subjects. The waist:hip ratio was higher in diabetic groups than non-diabetic subjects $(p=0.006)$. The diabetic subjects had higher fasting plasma glucose, glycated haemoglobin, serum cholesterol and triglycerides than non-diabetic subjects. Serum insulin concentrations and insulin resistance as calculated by HOMA were significantly higher in diabetic subjects than their non-diabetic counterparts.

The mean IMT in non-diabetic subjects was $0.74 \pm 0.14 \mathrm{~mm}$ and in diabetic subjects was $0.95 \pm 0.31 \mathrm{~mm}$. The range of IMT values in non-diabetic subjects was $0.5-1.2 \mathrm{~mm}$ and in diabetic subjects, $0.4-3.0 \mathrm{~mm}$. The prevalence of carotid atherosclerosis was determined based on the cut-off of $1.1 \mathrm{~mm}$ as described previously [2] which was also the lower limit of the fifth quintile of IMT values in our study population. Of the non-diabetic subjects $1 \%$ and of diabetic subjects $20 \%$ had carotid atherosclerosis $(p<0.001)$.

The mean values of IMT measurements in the newly diagnosed diabetic subjects was $0.87 \pm$ $0.26 \mathrm{~mm}$ whereas that of the known diabetic subjects was $0.98 \pm 0.34(p=0.04)$. Similarly the IMT of newly detected diabetic subjects was higher than the non-diabetic subjects $(p=0.002)$.

Figure 1 shows the distribution according to age of the mean IMT values in the diabetic and non-diabetic subjects. The IMT values were higher among the diabetic subjects at all age points compared with the non-diabetic subjects. At age 30 years or less, mean IMT of non-diabetic subjects was $0.60 \pm 0.08 \mathrm{~mm}$ and diabetic subjects was $0.63 \pm 0.06 \mathrm{~mm}$; at age $31-40$ years, non-diabetic subjects $0.67 \pm 0.14 \mathrm{~mm}$ and diabetic subjects $0.73 \pm 0.18 \mathrm{~mm}$; at age $41-$ 50 years, non-diabetic subjects $0.72 \pm 0.12 \mathrm{~mm}$ and diabetic subjects $0.87 \pm \pm 0.23 \mathrm{~mm}$; at age 5160 years, non-diabetic subjects $0.77 \pm 0.15 \mathrm{~mm}$ and diabetic subjects $0.97 \pm 0.27 \mathrm{~mm}$ and at age 61 years or more, non-diabetic subjects $0.81 \pm 0.13 \mathrm{~mm}$, diabetic subjects $1.1 \pm 0.37 \mathrm{~mm}$. The difference in IMT values between the study groups reached statistical significance after age 50 years $(p<0.05)$

The regression equation for diabetic subjects was $\mathrm{IMT}=0.37+$ age $(0.010)$ and for non-diabetic subjects, $\mathrm{IMT}=0.43+$ age $(0.0046)$.

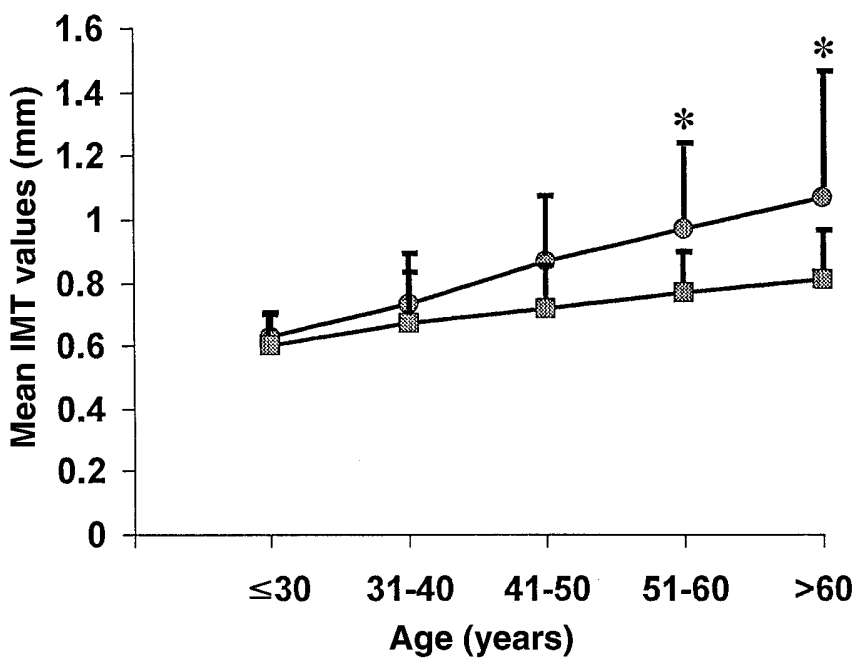

Fig. 1. Distribution by age of IMT in diabetic (n) and non-diabetic subjects (關). ${ }^{*} p<0.05$ compared with non-diabetic subjects 
Table 2. Correlation of IMT with the variables

\begin{tabular}{|c|c|c|c|c|}
\hline \multirow[t]{2}{*}{ Variables } & \multicolumn{2}{|c|}{ Non-diabetic subjects } & \multicolumn{2}{|c|}{ Diabetic subjects } \\
\hline & $r$ & $p$ & $r$ & $p$ \\
\hline Age & 0.49 & $<0.001$ & 0.44 & $<0.001$ \\
\hline Cholesterol & 0.31 & 0.02 & 0.024 & 0.409 \\
\hline LDL cholesterol & 0.33 & 0.014 & 0.013 & 0.45 \\
\hline HDL cholesterol & 0.009 & 0.48 & 0.29 & 0.31 \\
\hline Triglycerides & 0.08 & 0.20 & 0.059 & 0.27 \\
\hline $\mathrm{HbA}_{1 \mathrm{c}}$ & 0.18 & 0.13 & 0.13 & 0.10 \\
\hline Systolic BP & 0.34 & 0.012 & 0.114 & 0.126 \\
\hline Diastolic BP & 0.19 & 0.112 & 0.093 & 0.174 \\
\hline Fasting insulin & 0.07 & 0.33 & -0.075 & 0.23 \\
\hline Insulin resistance (HOMA) & -0.01 & 0.48 & -0.0017 & 0.49 \\
\hline
\end{tabular}

$\mathrm{BP}=$ blood pressure

Table 3. Multivariate linear regression analysis using IMT as dependent variable

\begin{tabular}{lllc}
\hline Variables & $\beta$ & $\mathrm{SE} \beta$ & $p$ value \\
\hline Age & 0.007 & 0.001 & $<0.001$ \\
Diabetes & 0.126 & 0.043 & 0.003 \\
HbA $_{1 \mathrm{c}}$ & 0.019 & 0.010 & 0.06 \\
Cholesterol $_{\text {HDL cholesterol }}$ & 0.00004 & 0.00004 & 0.24 \\
\hline
\end{tabular}

The prevalence of hypertension in diabetic subjects was $31.4 \%$ and non-diabetic subjects, $23.3 \%$. The mean IMT values in the non-diabetic subjects without and with hypertension were $0.74 \pm 0.15 \mathrm{~mm}$ and $0.78 \pm 0.12 \mathrm{~mm}$, respectively. In the diabetic subjects without and with hypertension, the mean IMT values were $0.94 \pm 0.32 \mathrm{~mm}$ and $1.0 \pm 0.26 \mathrm{~mm}$. None of the above differences however reached statistical significance.

Table 2 presents the correlation of IMT with the variables studied. In the non-diabetic subjects age, cholesterol, LDL cholesterol, waist:hip ratio and systolic blood pressure had a positive correlation with IMT whereas in diabetic subjects, age and duration of diabetes had a positive correlation with IMT.

Multivariate linear regression analysis was done combining the data on diabetic and non-diabetic subjects and including diabetes as an independent variable. Age and diabetes showed an association with IMT (Table 3).

Table 4 presents a survey of the literature showing intimal medial thickness reported in diabetic and non-diabetic subjects in different populations. The mean IMT values of both diabetic and non-diabetic subjects seem to be higher in our study than in earlier studies. Large differences in methodology, instrumentation and interobserver variations could explain this.

\section{Discussion}

Intimal medial thickness of the common carotid artery is considered to be an excellent non-invasive measure of generalised atherosclerosis [1-3,18,19] and also a surrogate marker of coronary artery disease [20-22]. It is also extensively used to examine the stage of atherosclerosis and to evaluate the regression of atherosclerotic lesions in intervention therapies [23-25]. The International Atherosclerosis Project [26] has suggested that the carotid and cerebral arteries and the aorta undergo the atherosclerotic process approximately at the same age as the coronary arteries. Moreover there is good agreement between histological examination and the ultrasonographic evaluation of carotid arteries [27].

Earlier studies have reported ethnic differences in coronary artery disease morbidity and mortality $[28,6,7]$. Similarly ethnic differences in carotid wall thickness were reported in the IRA Study [29] where blacks were found to have increased IMT values compared with non-hispanic whites [29]. In the Atheroslerosis risk in communities (ARIC) Study also, differences were found with respect to family history of coronary artery disease and IMT among blacks and whites [30]. These ethnic differences emphasize the need for studies on IMT in different populations. This study presents data on intimal medial thickness in Asian Indians. Asian Indians are of particular interest because of the very high prevalence rates of premature coronary artery disease [6-8] and diabetes $[9,10]$. Moreover, higher plasma insulin concentrations [31] and increased insulin resistance have been noted in this ethnic group [32]. Recent studies have also reported a clustering of cardiovascular risk factors in this population [33]. Moreover, although the prevalence of coronary artery disease is high, that of peripheral vascular disease seems to be low [34]. This points to differences in the profile of macrovascular disease among Indians. In this context, studies 
Table 4. Intimal medial thickness (IMT) in diabetic and non-diabetic subjects from various studies

\begin{tabular}{|c|c|c|c|c|c|}
\hline Reference & $n$ & Characteristics & $\begin{array}{l}\text { Age } \\
\text { (Yrs) }\end{array}$ & $\begin{array}{l}\text { IMT } \\
\text { (Unadjusted, mm) }\end{array}$ & Type of measurement \\
\hline Kawamori et al. [2] & $\begin{array}{r}275 \\
71\end{array}$ & $\begin{array}{l}\text { Type II diabetes } \\
\text { Non-diabetic subjects }\end{array}$ & $\begin{array}{l}31-89 \\
20-79\end{array}$ & $\begin{array}{l}0.73 \pm 0.27 \\
0.52 \pm 0.07\end{array}$ & $\begin{array}{l}\text { Extracranial carotids; } \\
\text { maximum of six measurements }\end{array}$ \\
\hline Pujia et al. [44] & $\begin{array}{l}54 \\
54\end{array}$ & $\begin{array}{l}\text { Type II diabetes } \\
\text { Age/sex matched } \\
\text { control subjects }\end{array}$ & $54 \pm 9$ & $\begin{array}{l}0.77 \pm 0.13 \\
0.69 \pm 0.10\end{array}$ & $\begin{array}{l}\text { Common carotid artery; } \\
\text { mean over } 1 \mathrm{~cm}\end{array}$ \\
\hline Yamasaki et al. [17] & $\begin{array}{l}14 \\
12\end{array}$ & $\begin{array}{l}\text { Type II diabetes } \\
\text { Non-diabetic subjects }\end{array}$ & $\begin{array}{l}30-39 \\
30-39\end{array}$ & $\begin{array}{l}0.92 \pm 0.14 \\
0.64 \pm 0.12\end{array}$ & $\begin{array}{l}\text { Extracranial carotids, } \\
\text { maximum of six means }\end{array}$ \\
\hline Kanters et al. [37] & 56 & Type II diabetes & $\begin{array}{c}37-73 \\
58 \pm 8\end{array}$ & $1.00 \pm 0.43$ & Maximum of six means \\
\hline Our study & $\begin{array}{l}140 \\
103\end{array}$ & $\begin{array}{l}\text { Type II diabetes } \\
\text { Age/sex matched } \\
\text { control subjects }\end{array}$ & $\begin{array}{l}55 \pm 12 \\
(27-84) \\
52 \pm 13 \\
(26-84)\end{array}$ & $\begin{array}{l}0.95 \pm 0.31 \\
0.74 \pm 0.14\end{array}$ & $\begin{array}{l}\text { Common carotid artery, mean of six } \\
\text { measurements }\end{array}$ \\
\hline
\end{tabular}

of intimal medial thickness assume great importance in this population.

This study shows that IMT is increased in diabetic patients compared with non-diabetic subjects both in men and women. Moreover, at every age point, diabetic patients had increased IMT compared with their non-diabetic counterparts.

Age, serum cholesterol, LDL cholesterol, waist: hip ratio and systolic blood pressure showed a statistically significant correlation with IMT in non-diabetic subjects. In diabetic subjects, only age and duration of diabetes showed a significant correlation with IMT. The reason the other variables were not correlated in diabetic subjects could be explained by the fact that diabetes itself turned out to be an independent risk factor in the multivariate linear regression analysis and in diabetic subjects, total cholesterol, LDL cholesterol, waist: hip ratio and systolic blood pressure were already higher than in non-diabetic subjects.

Age shows a correlation with IMT both in diabetic and non-diabetic subjects but the regression equation is different in the two groups and the process seems to be accelerated to a greater extent in diabetic than in non-diabetic subjects. Diabetic patients are known to have a higher frequency of atherosclerosis and diabetic subjects show atherosclerosis in carotid arteries 20-30 years earlier than non-diabetic subjects [2].

The risk factors for increased IMT in diabetic patients seem to be different in various studies. One reported that age, duration of diabetes, smoking, hypertension and hyperlipidaemia were independently related to IMT in diabetic subjects [2]. Another found that none of the potential risk factors were associated with IMT in diabetic subjects [35]. Age alone has been found to be an independent predictor for IMT [36] and diabetes as well as ageing to advance atherosclerosis in the carotid arteries [17]. Some researchers [37] showed that none of the variables were associated with IMT in Type II diabetes whereas the age and $\mathrm{HbA}_{1 \mathrm{c}}$ were identified as the risk factors for IMT in Type I (insulin-dependent) diabetic patients.

Insulin sensitivity and insulin resistance have been reported to be associated with cardiovascular risk and also with IMT in some studies [38-40]. In our study insulin resistance as assessed by HOMA showed no association with IMT. Ethnic differences in the association of insulin sensitivity and atherosclerosis have been reported in the IRAS study [41]. Moreover, relative fasting hypoinsulinaemia has been reported to be related to carotid wall thickening in Type II diabetes [42].

The predictive power of IMT for the risk of myocardial infarction and stroke is well established [4, 43]. Both these studies were carried out on an elderly population. Follow-up studies are required to identify whether IMT is a predictor of macrovascular sequelae in this Asian Indian population.

\section{References}

1. Pignoli P (1984) Ultrasound B-mode imaging for arterial wall thickness measurement. Atheroscler Rev 12: 177-184

2. Kawamori R, Yamasaki Y, Matsushima H et al. (1992) Prevalence of Carotid atherosclerosis in diabetic patients. Diabetes Care 15: 1290-1294

3. Grobbee DE, Bots ML (1994) Carotid artery intima - media thickness as an indicator of generalized atherosclerosis. J Intern Med 236: 567-573

4. O'Leary DH, Polak JJF, Kronmal RA et al. (1999) Carotid artery intima and media thickness as a risk factor for myocardial infarction and stroke in older adults. N Eng J Med 340: $14-22$ 
5. Hodis HN, Mack WJ, LaBree L et al. (1998) The role of carotid arterial intima-media thickness in predicting clinical coronary events. Ann Intern Med 128: 262-269

6. Mckeigue PM, Miller GJ, Marmot MG (1989) Coronary artery disease in South Asian overseas: a review. J Clin Epidemiol 41: 597-598

7. Balarajan R (1991) Ethnic differences in mortality from ischaemic heart disease in England and Wales. BMJ 302: 560-564

8. Beckles GLA, Miller GJ, Kirkwood BR et al. (1986) High total and cardiovascular disease mortality in adults of Indian descent in Trinidad, unexplained by major coronary risk factors. Lancet I:1289-1301

9. Ramachandran A, Jali MV, Mohan V, Snehalatha C, Viswanathan M (1988) High prevalance of diabetes in an urban population in south India. BMJ 297: 587-590

10. Mather HM, Keen H (1985) The Southall diabetes survey: prevalence of known diabetes in Asians and Europeans. BMJ 291: 1081-1084

11. Ramachandran A (1997) Rising prevalence of NIDDM in an urban population in India. Diabetologia 40: 232-237

12. King H, Auberti RE, Herman WH (1998) Global burden of diabetes, 1995-2025-prevalence, numerical estimates and projections. Diabetes Care 21: 1414-1431

13. Friedewald WT, Levy RI, Fredrickson DS (1972) Estimation of the concentration of low density lipoprotein cholesterol in plasma without use of the preparative ultracentrifuge. Clin Chem 18: 499-502

14. Haffner SM, Miettinen H, Stern MP (1997) The homeostasis model in the San Antonio Heart Study. Diabetes Care 20: 1087-1092

15. Alberti KGMM, Zimmet PZ (1998) Definition diagnosis and classification of diabetes mellitus and its complications. Part 1: Diagnosis and classification of diabetes mellitus. Provisional report of a WHO Consultation. Diabet Med 15: 539-553

16. Pignoli P, Tremoli E, Poli A, Oreste P, Paoletti R (1986) Intimal plus medial thickness of the arterial wall: a direct measurement with ultrasound imaging. Circulation 74: 1399-1407

17. Yamasaki Y, Kawamori R, Matsushima H et al. (1994) Atherosclerosis in carotid artery of young IDDM patients monitored by ultrasound high resolution B-mode imaging. Diabetes 43: 634-639

18. Riley WA, Barnes RW, Evans GW, Burke GL (1992) Ultrasonic measurement of the elastic modulus of the common carotid artery. Stroke. 23: 952-956

19. Wofford JL, Kahl FR, Howard GR et al. (1991) Relation of extent of extracranial carotid artery atherosclerosis as measured by B-mode ultrasound to the extent of coronary atherosclerosis. Arterioscler Thromb 11: 1786-1794

20. O'Leary DH, Polak JF, Kronmal RA et al. (1992) Distribution and correlates of sonographically detected carotid artery disease in the Cardiovascular Health Study. Stroke 23: $1752-1760$

21. Geroulakos G, O'Gorman D, Nocolaides A, Sheridan D, Elkeles R, Shaper AG (1994) Carotid intima media thickness: correlation with the British Regional Heart Study risk score. J Intern Med 5: 431-433

22. Ebrahim S, Papacosta O, Whincup P et al. (1999) Carotid plaque, intima media thickness, cardiovascular risk factors and prevalent cardiovascular disease in men and women: The British Regional Heart Study. Stroke 30: 841-850

23. Migdalis IN, Gerolimou BM, Kozanidou G, Hatzigakis SM, Karmaniolas KD (1997) Effect of fosinopril sodium on early carotid atherosclerosis in diabetic patients with hypertension. J Med 28: 371-380

24. Migdalis IN, Gerolimou BM, Kozanidou G, Voudouris G, Hatzigakis SM, Petropoulos A (1997) Effect of gemfibrozil on early carotid atherosclerosis in diabetic patients with hyperlipidaemia. Int Angiol 16: 258-261
25. Minamikawa J, Tanaka S, Yamauchi M, Inoue D, Koshiyama H (1998) Potent inhibitory effect of troglitazone on cartoid arterial wall thickness in type 2 diabetes. J Clin Endocrinol Metab 83: 1818-1820

26. McGarry PA, McMahan CA, Montenegro MR et al. (1968) General findings of the International Atherosclerosis Project. Lab Invest 18: 498-502

27. Wong M, Edelstein J, Wollman J, Bond G (1993) Ultrasonicpathological comparsion of the human arterial wall: verification of intima-media thickness. Arterioscler Thromb 3: 482-486

28. Gillium FR (1991) Cardiovascular disease in the United States: an epidemiologic overview. Cardiovasc Clin 21: 3-6

29. D’Agostino RB, Burke G, O'Leary DH et al. (1996) Ethnic differences in cartoid wall thickness - The insulin resistance atherosclerosis study. Stroke 27: 1744-1749

30. Bensen JT, Li R, Hutchinson RG, Province MA, Tyroler HA (1999) Family history of coronary heart disease and pre clinical cartoid artery atherosclerosis in African Americans and Whites: the ARIC study: Artherosclerosis risk in communities. Genet Epidemiol 16: 165-178

31. Mohan V, Sharp PS, Cloke HR, Burrin JM, Scheumer B and Kohner EM (1986) Serum immunoreactive insulin response to a glucose load in Asian Indian and European Type II (non-insulin-dependent) diabetic patients and control subjetcs. Diabetologia 29: 235-237

32. Sharp PS, Mohan V, Levy JC, Mather HM, Kohner EM (1987) Insulin resistance in patients of Asian Indian and European origin with non insulin dependent diabetes. Horm Metab Res 19: 84-85

33. Ramachandaran A, Snehalatha C, Latha E, Satyavani K, Vijay V (1998) Clustering of cardiovascular risk factors in urban Asian Indians. Diabetes Care 21: 967-971

34. Mohan V, Premalatha G, Sastry NG (1995) Peripheral vascular disease in non insulin dependent diabetes mellitus in South India. Diabetes Res Clin Pract 27: 235-240

35. Geroulakos G, Ramaswami G, Veller MG et al. (1994) Arterial wall changes in type 2 diabetic subjects. Diabet Med 11: 692-695

36. Merrin PK, Renton S, Fisher C et al. (1994) Serum lipids and apolipoproteins and their relationship with macrovascular disease in type 1 diabetes. Diabet Med 11: 402-406

37. Kanters SDJM, Algra A, Banga JD (1997) Carotid intimamedia thickness in hyperlipidemic type 1 and type 2 diabetic patients. Diabetes Care. 20: 276-280

38. Bonora E, Tessari R, Micciolo R et al. (1997) Intimal medial thickness of the carotid artery in non-diabetic and NIDDM patients - Relationship with insulin resistance. Diabetes Care. 20: 627-631

39. Reaven GM, Chen YDI (1996) Insulin resistance, its consequences and coronary heart disease. Must we choose one culprit? Circulation 93: 1780-1783

40. Fujii K, Abe I, Ohya Y et al. (1997) Association between hyperinsulinemia and intima-media thickness of the carotid artery in normotensive men. J Hypertens 15: 167-172

41. Howard G, O'Leary DH, Zaccaro D et al. (1996) Insulin sensitivity and atherosclerosis: The Insulin Resistance Atherosclerosis Study (IRAS) investigators. Circulation 15: 1809-1817

42. Elkeles RS, Diamond JR, El-Bahghouti N et al. (1996) Relative fasting hypoinsulinemia and ultrasonically measured early arterial disease in type 2 diabetes. The SENDCAP study Group, St. Mary's, Ealing, Northwick Park Diabetes Cardiovascular Disease Prevention Study. Diabet Med 13: 247-253

43. Hofman A, Grobbee DE, de Jong PT, van den Ouweland FA (1991) Determinants of disease and disability in the elderly: the Rotterdam Elderly Study. Eur J Epidemiol 7: 403-422

44. Pujia A, Gnasso A, Irace C, Colonna A, Mattioli PL (1994) Common carotid arterial wall thickness in NIDDM subjects. Diabetes Care 17: 1330-1336 